\title{
Risk Factor Analysis of Proximal Junctional Kyphosis after Surgical Treatment of Adult Spinal Deformity with Oblique Lateral Interbody Fusion
}

\author{
Yoshinao Koike $^{1}$, Yoshihisa Kotani ${ }^{1,2}$, Hidemasa Terao $^{1,3}$, Norimasa Iwasaki ${ }^{3}$ \\ ${ }^{1}$ Spine and Spinal Cord Center, Department of Orthopaedic Surgery, Steel Memorial Muroran Hospital, Muroran, Japan \\ ${ }^{2}$ Department of Orthopedic Surgery, Kansai Medical University Medical Center, Moriguchi, Japan \\ ${ }^{3}$ Department of Orthopedic Surgery, Hokkaido University Graduate School of Medicine, Sapporo, Japan
}

\section{Study Design: A single-center retrospective study.}

Purpose: To investigate the prevalence of proximal junctional kyphosis (PJK) and its risk factors after surgical treatment of adult spinal deformity (ASD) with oblique lateral interbody fusion (OLIF).

Overview of Literature: Correction of ASD using OLIF has been developed because it is less invasive, and enables correction of severe deformities. Although PJK is a well-recognized complication after the correction of spinal deformity, few studies have evaluated the prevalence and risk factors for PJK after OLIF for ASD.

Methods: We reviewed 74 patients who underwent surgery for ASD. PJK was defined as a proximal junction sagittal Cobb angle exceeding $10^{\circ}$, and at least $10^{\circ}$ greater than the preoperative measurement. We investigated the following as risk factors: age, sex, body mass index, medical history, number of fused segments, number of interbody fusions, number of OLIFs, number of osteotomies, level of upper instrumented vertebrae, lowest instrumented vertebrae, and radiographic parameters.

Results: The mean follow-up duration was 22.4 months and the mean age of the patients was 73.6 years. PJK was present in 19/74 patients $(25.7 \%)$ and absent in $55 / 74(74.3 \%)$. In the univariate analysis, those with PJK had a significantly higher proportion of patients with a history of vertebral compression fracture (7/19 patients [36.8\%] vs. $6 / 55$ patients [10.9\%], $p=0.027)$. Those with PJK had a significantly higher proportion of patients with fusion to the pelvis (18/19 patients [94.7\%] vs. $34 / 55$ patients [61.8\%], $p=0.016)$. According to the multivariate analysis, fusion to the pelvis was a significant risk factor for PJK.

Conclusions: Fusion to the pelvis was the most important risk factor for PJK. A history of vertebral compression fracture served as an additional risk factor for PJK. Clinicians should consider these factors before treating ASD patients with OLIF.

Keywords: Oblique lateral interbody fusion; Lateral lumbar interbody fusion; Proximal junctional kyphosis; Proximal junctional failure; Adult spinal deformity

Received Oct 29, 2019; Revised Feb 5, 2020; Accepted Mar 1, 2020

Corresponding author: Yoshinao Koike

Spine and Spinal Cord Center, Department of Orthopaedic Surgery, Steel Memorial Muroran Hospital, 1-45, Chiribetsu-cho, Muroran, Hokkaido 050-0076, Japan

Tel: +81-143-44-4650, Fax: +81-143-47-0990, E-mail: yoshinao.koi@gmail.com

Co-corresponding author: Yoshihisa Kotani

Department of Orthopedic Surgery, Kansai Medical University Medical Center, 10-15, Fumizono-cho, Moriguchi, Osaka 570-8507, Japan

Tel: +81-6-6992-1001, Fax: +81-6-6992-4846, E-mail: yoshi96k@ja2.so-net.ne.jp 


\section{Introduction}

Adult spinal deformity (ASD) is a common disorder with symptoms of pain and disability, and prominently affects patients' quality of life as they get older [1,2]. Although surgical deformity correction has been proven to be effective for improving patient-reported outcomes [3], it is challenging because the incidence of complications is relatively high [4]. Traditional open posterior surgical procedures carry a high risk of neurologic damage, and have an excessive bleeding risk $[5,6]$.

Lateral lumbar interbody fusion (LLIF), which uses a minimally invasive lateral retroperitoneal technique to accomplish interbody fusion, has been developed and applied in ASD as an alternative surgical option to avoid the morbidity from traditional open surgery $[7,8]$. This approach allows direct access to the disc space and placement of a large interbody graft, enables aggressive deformity correction of ASD [7,8], and achieves a high fusion rate [9]. Oblique lateral interbody fusion (OLIF), performed by an oblique retroperitoneal psoas-preserving approach, allows comprehensive disc space clearance, and avoids damaging the neural structures and psoas muscle [10].

Proximal junctional kyphosis (PJK) is a well-recognized complication after long-segment instrumentation for the correction of spinal deformity [11]. The definition of PJK by Glattes et al. [11] is most commonly used, with PJK considered to be present when the sagittal Cobb angle between the upper instrumented vertebrae (UIV) and two supra-adjacent vertebrae exceeds $10^{\circ}$. Approximately $17 \%$ to $41 \%$ of patients who undergo long-segment instrumentation for deformity develop PJK [11-17], and many risk factors for PJK have been identified [12-19].

Spinal deformity correction surgery with OLIF is relatively less invasive compared with the traditional posterior surgical procedure, and we have extended the indications to include older patients. However, older age $[12,14]$ and greater spinal curvature correction are risk factors for PJK $[14,15]$, and we were concerned about the possibility that correction surgery with OLIF would carry a notable risk of PJK. So, our study aimed to investigate the prevalence of PJK and its risk factors after surgical treatment for ASD using OLIF.

\section{Materials and Methods}

All procedures were in accordance with the ethical standards of the institutional and/or national research committee (Steel Memorial Muroran Hospital Institutional Review Board approval no., J180605) and with the 1964 Helsinki Declaration and its later amendments. Patients were informed that their data would be used for clinical research purposes and gave their consent.

We retrospectively reviewed 80 consecutive patients who underwent primary surgical treatment of their spinal deformity at a single medical center (Steel Memorial Muroran Hospital) from 2012 through 2017. The inclusion criteria were: diagnosis of adult idiopathic scoliosis or adult degenerative scoliosis; corrective surgery using OLIF; age more than 50 years at the time of surgery; minimum of five vertebrae fused from the UIV; and minimum of 1-year follow-up. Exceptionally, patients who underwent a second operation because of proximal junctional failure (PJF) within 1-year follow-up were included, and evaluation was performed using data up to the second surgery. Patients with spinal infection, tumor, and acute vertebral fractures of the thoracic and lumbar spine were excluded.

As six of 80 patients were lost to follow-up, clinical information was available for 74 patients (92.5\%). The study included nine male and 65 female patients. Their mean age at surgery was 73.6 years (range, $52-84$ years). All procedures were performed by a single surgeon.

Radiographic measurements obtained from preoperative, early postoperative, and final follow-up radiographs were analyzed. We divided the subjects into PJK and noPJK groups, and investigated the following patient and surgical risk factors: age; sex; body mass index (weight $[\mathrm{kg}] /$ height $\left.{ }^{2}\left[\mathrm{~m}^{2}\right]\right)$; history of neurodegenerative disease (e.g., Parkinson's disease); collagen disease (e.g., rheumatoid arthritis); vertebral compression fracture (VCF); proximal femoral fracture; number of fused segments; number of interbody fusions; number of OLIFs; number of osteotomies; level of UIV; lowest instrumented vertebrae (LIV); and preoperative and postoperative radiographic parameters.

\section{Surgical procedure}

We planned single or staged surgery according to the patient's preoperative general status and the invasiveness of the surgery. In each procedure, we first performed OLIF 
in the lateral position. In OLIF, adequate discectomy was performed under direct visualization, and polyether ether ketone cages with allograft were placed in the disc spaces. If there was a severe VCF with local kyphosis, corpectomy and placement of a vertebral body replacement cage with allograft was performed for deformity correction. In single-stage surgery, after changing to the prone position, posterior surgery was performed. In staged surgery, patients wore a hard brace, and their activity was restricted to a wheelchair while waiting for the second-stage posterior surgery, which was performed in the prone position a week after the first-stage surgery. In posterior surgery, fixation points were obtained using modified cortical bone trajectory screws, as previously reported [20]. A posterior column osteotomy (PCO), and additional transforaminal interbody fusion (TLIF) was selected as the corrective technique based on patient characteristics for each case. Posterior osteotomy other than PCO (e.g., posterior vertebral column resection and pedicle subtraction osteotomy) was not performed in any case. Hybrid posterior minimally invasive surgery (consisting of lumbosacral open TLIF combined with percutaneous screw) was used for many cases. In rigid deformity or severely imbalanced cases, full open posterior correction and fusion was performed. In either technique, multiple methods were used to accomplish correction of the deformity, such as the rod cantilever technique, in situ bending, and rod de-rotation technique.

Regarding the level of the LIV, at first fusion to the pelvis was not performed for patients with milder deformity and without distal junctional degeneration, to preserve intervertebral mobility. However, several patients needed revision surgery because of insufficient primary deformity correction, or distal adjacent segment disease in the early follow-up period. Therefore, we have performed fusion to the pelvis for all ASD patients with more than five instrumented spinal levels since 2015.

All surgical procedures were performed under intraoperative three-dimensional computed tomography navigation (O-arm; Medtronic, Minneapolis, MN, USA). Postoperatively, patients refrained from walking with a hard brace for 1 week. If there was no problem according to radiography performed 1 week after the surgery, the patient was allowed to walk with a hard brace. Patients were required to wear the brace for 2 months postoperatively.

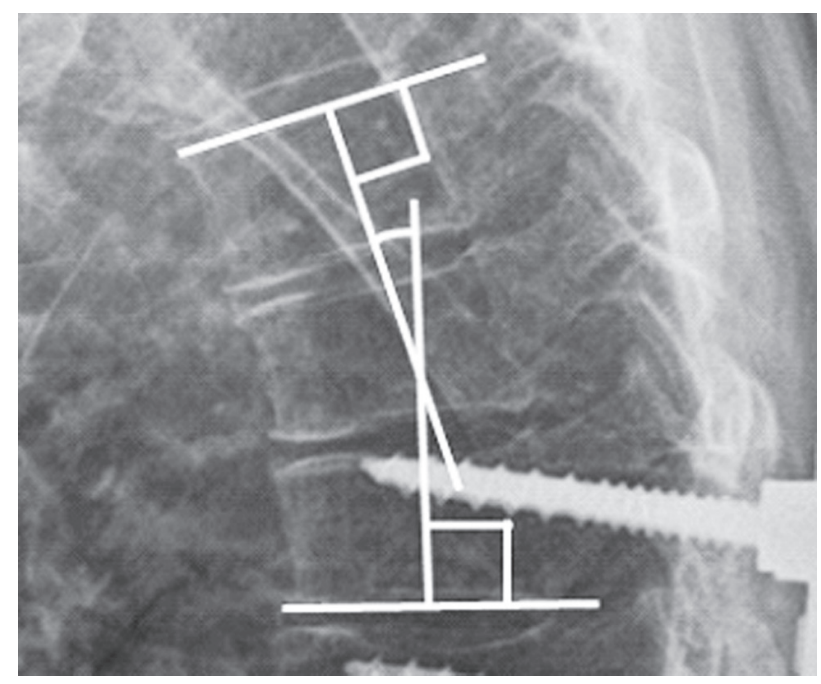

Fig. 1. Proximal junction sagittal Cobb measurement. Proximal junctional kyphosis was measured from the inferior endplate of the upper instrumented vertebra to the superior endplate of the second vertebrae above.

\section{Radiographic measurements}

All patients underwent radiography in the standing posteroanterior and lateral positions using the $91.44 \mathrm{~cm}$-long cassette. On the lateral radiographs, the proximal junctional angle (PJA) was defined as the angle between the caudal endplate of the UIV to the cephalad endplate two vertebrae proximally (UIV-2) (Fig. 1). PJK was defined as PJA exceeding $10^{\circ}$, and at least $10^{\circ}$ greater than the preoperative measurement as reported by Glattes et al. [11]. PJF was defined as any type of symptomatic PJK along with fracture of the vertebral body of UIV or UIV-1, or implant failure at the UIV requiring surgery. The sagittal vertical axis was measured as the distance from the $\mathrm{C} 7$ plumb line to the posterosuperior corner of the sacrum. Thoracic kyphosis was measured from the cephalad endplate of T5 to the caudal endplate of T12. Lumbar lordosis was measured from the cephalad endplate of L1 to the cephalad endplate of S1. Concerning pelvic measurements, pelvic incidence was measured as the angle between the point perpendicular to the cephalad S1 endplate at its midpoint, and the line connecting this point to the center of the femoral heads. Pelvic tilt was measured as the angle between the vertical line and the line through the midpoint of the sacral endplate to the axis of the femoral heads.

On the posteroanterior radiographs, the Cobb angle of the main curve was measured. Coronal vertical axis was measured as the distance from the $\mathrm{C} 7$ plumb line to the central sacral vertical line. 


\section{Patient outcomes}

For clinical evaluation, the Japanese Orthopedic Association Back Pain Evaluation Questionnaire (JOABPEQ), which is an evaluation scale based on self-reported questionnaires, and a Visual Analog Scale (VAS, 0-100) to assess low back pain, leg pain, and leg numbness were administered before surgery, and at 1 year postoperatively. The JOABPEQ comprises five domains (low back pain, lumbar function, walking ability, social life function, and mental health) and 25 questionnaire items. The evaluation items were assessed for each domain, and the score is represented by 0-100 points in each domain (higher score means better function) [21]. When evaluating the therapeutic effect of a treatment using JOABPEQ, if the score after the treatment improves by 20 points or more compared to before treatment, or if the score before the treatment is less than 90 points and it is 90 points or more after treatment, treatment is judged to be effective [21].

\section{Statistical analysis}

For categorical variables, statistical comparisons between the PJK and no-PJK group were evaluated using chisquare tests, or chi-square tests with Yates' correction when expected numbers were small. For continuous variables, differences between groups were evaluated with the two-sample $t$-test. Differences in preoperative JOABPEQ score between the groups were evaluated with the MannWhitney $U$-test, and differences in JOABPEQ effective- ness rate were evaluated with the test of population proportion.

After these univariate analyses, regarding risk factors for PJK, variables with a $p$-value $<0.20$ were selected and evaluated by multivariate logistic regression analysis. The data were analyzed using StatMate ver. 5.01 (ATMS Co. Ltd., Tokyo, Japan). A $p$-value $<0.05$ was considered statistically significant.

\section{Results}

PJK was noted in 19 of 74 patients (25.7\%) and PJF was noted in six of 74 patients $(8.1 \%)$ at the final follow-up (Fig. 2). The mean follow-up duration was 22.4 months (the PJK group: 17.4 months; range, 1-53 months; the no-PJK group: 24.1 months; range, $12-64$ months). The average number of fused segments was 7.7 (range, 4-15). Concerning UIV, the number of patients with fusion to the upper thoracic vertebrae (T5 or above) was 9 , mid to lower thoracic vertebrae (T6-T11) was 39, and thoracolumbar vertebrae (below T12) was 26. Regarding LIV, the number of patients with fusion to the lumbar vertebrae was 22 (L4: 1, L5: 21), and to the pelvis was 52 (sacrum: 1, ilium: 51).

In the univariate analysis, the PJK group (7/19 patients, $36.8 \%$ ), compared to the no-PJK group (6/55 patients, $10.9 \%)$, demonstrated a significantly higher proportion of patients with a history of VCF $(p=0.027)$ (Table 1$)$. Regarding fusion level, the PJK group demonstrated a significantly higher proportion of patients with fusion to the
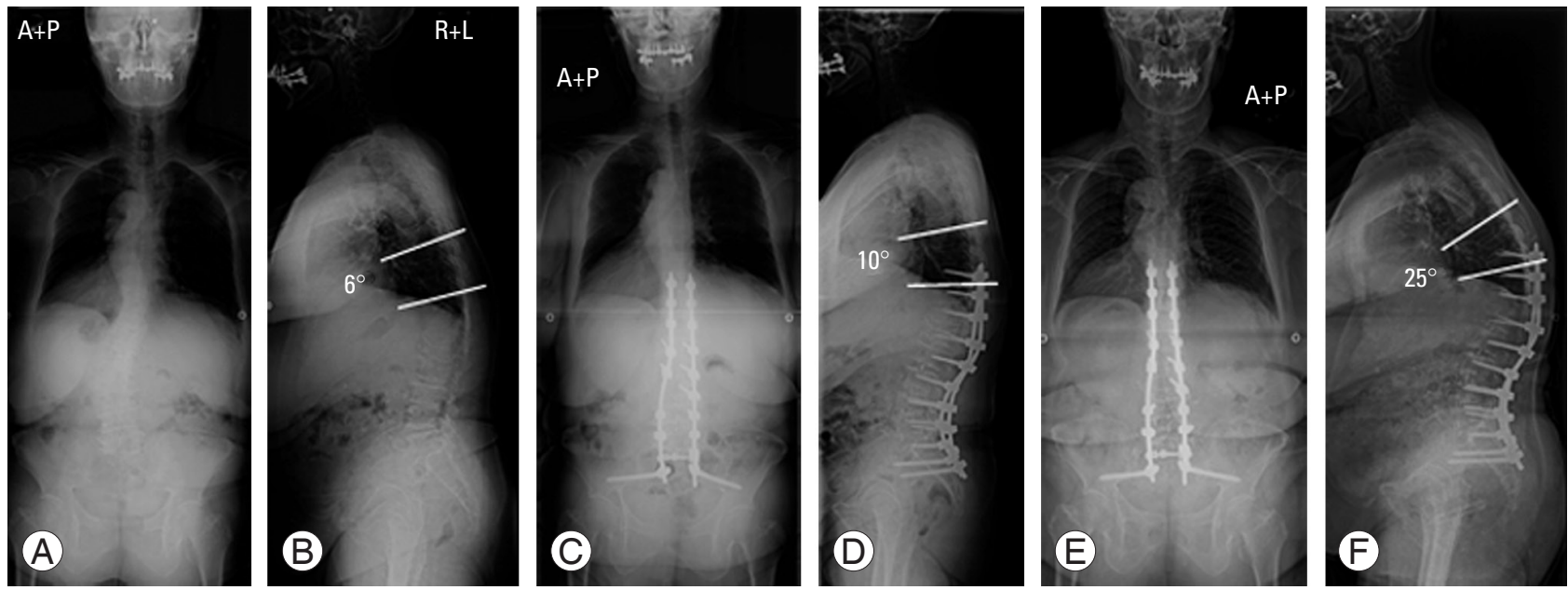

Fig. 2. Case of proximal junctional kyphosis. A 70-year-old female patient with adult degenerative scoliosis who underwent deformity correction surgery using oblique lateral interbody fusion. (A, B) Preoperative radiographs. (C, D) Postoperative radiographs 1 week after surgery. (E, F) Follow-up radiographs 16 months after surgery. Proximal junctional kyphosis has occurred. A, anterior; P, posterior; R, right; L, left. 
pelvis (18/19 patients, 94.7\%) than the no-PJK group (34/55 patients, $61.8 \%$; $p=0.016$ ) (Table 2). No between-group difference was observed with respect to radiographic parameters, other than PJA at final follow-up (Table 3). According to multivariate logistic regression analysis, fusion to the

Table 1. Comparison of patient factors between the PJK and no-PJK groups

\begin{tabular}{lccc} 
Characteristic & $\begin{array}{c}\text { PJK } \\
(\mathrm{n}=19)\end{array}$ & $\begin{array}{c}\text { No-PJK } \\
(\mathrm{n}=55)\end{array}$ & $p$-value \\
\hline Age $(\mathrm{yr})$ & $72.9 \pm 8.9$ & $73.8 \pm 6.4$ & 0.710 \\
\hline Sex & 3 & 6 & 0.878 \\
\hline \multicolumn{1}{|c}{ Male } & 16 & 49 & \\
\hline Female & $23.6 \pm 4.3$ & $22.6 \pm 3.2$ & 0.384 \\
\hline Body mass index $\left(\mathrm{kg} / \mathrm{m}^{2}\right)$ & & & \\
\hline History & 1 & 2 & 0.715 \\
\hline$\quad$ Neurodegenerative disease & 2 & 1 & 0.325 \\
\hline Collagen disease & 7 & 6 & $0.027^{\mathrm{a})}$ \\
\hline Vertebral compression fracture & 0 & 1 & 0.575 \\
\hline Proximal femoral fracture & & & \\
\hline
\end{tabular}

Values are presented as mean \pm standard deviation or number.

PJK, proximal junctional kyphosis.

alIndicates a statistically significant difference.

Table 2. Comparison of surgical factors between the PJK and no-PJK groups

\begin{tabular}{lccc} 
Variable & $\begin{array}{c}\text { PJK } \\
(\mathrm{n}=19)\end{array}$ & $\begin{array}{c}\text { No-PJK } \\
(\mathrm{n}=55)\end{array}$ & $p$-value \\
\hline No. of fused segments & $8.3 \pm 2.8$ & $7.5 \pm 3.2$ & 0.386 \\
\hline No. of interbody fusions & $5.1 \pm 1.3$ & $4.6 \pm 1.3$ & 0.156 \\
\hline No. of oblique lateral interbody fusions & $4.3 \pm 1.1$ & $4.0 \pm 1.1$ & 0.300 \\
\hline Corpectomies & 3 & 1 & 0.083 \\
\hline Posterior column osteotomy & 2 & 6 & 0.702 \\
\hline Upper instrumented vertebrae & & & \\
\hline- T5 & 2 & 7 & 0.562 \\
\hline T6-T11 & 12 & 27 & \\
\hline T12- & 5 & 21 & \\
\hline Lowest instrumented vertebrae & & & \\
\hline Lumbar & 1 & 21 & $0.016^{a)}$ \\
\hline Pelvis & 18 & 34 & \\
\hline Posterior procedure & & & \\
\hline All percutaneous & 1 & 6 & 0.759 \\
\hline Hybrid & 16 & 43 & \\
\hline Full open & 2 & 6 & \\
\hline
\end{tabular}

Values are presented as mean \pm standard deviation or number.

PJK, proximal junctional kyphosis.

${ }^{a}$ Indicates a statistically significant difference.
Table 3. Comparison of radiographic parameters between the PJK and no-PJK groups

\begin{tabular}{|c|c|c|}
\hline Variable & $\begin{array}{c}\text { PJK } \\
(n=19)\end{array}$ & $\begin{array}{c}\text { No-PJK } \\
(n=55)\end{array}$ \\
\hline
\end{tabular}

Sagittal vertical axis $(\mathrm{mm})$

\begin{tabular}{|c|c|c|c|}
\hline Preop & $110.0 \pm 62.3$ & $114.6 \pm 94.6$ & 0.813 \\
\hline Postop & $64.3 \pm 40.0$ & $56.8 \pm 46.5$ & 0.495 \\
\hline Follow-up & $85.6 \pm 72.0$ & $57.7 \pm 44.0$ & 0.133 \\
\hline Change $e^{a)}$ & $50.6 \pm 80.5$ & $57.8 \pm 91.3$ & 0.766 \\
\hline \multicolumn{4}{|c|}{ Coronal vertical axis $(\mathrm{mm})$} \\
\hline Preop & $24.3 \pm 31.7$ & $25.4 \pm 21.8$ & 0.895 \\
\hline Postop & $20.5 \pm 16.3$ & $22.7 \pm 17.6$ & 0.631 \\
\hline Follow-up & $11.4 \pm 13.2$ & $15.8 \pm 15.2$ & 0.257 \\
\hline Changeal & $12.3 \pm 40.8$ & $12.7 \pm 32.4$ & 0.966 \\
\hline \multicolumn{4}{|l|}{ Cobb angle $\left({ }^{\circ}\right)^{b)}$} \\
\hline Preop & $25.0 \pm 16.3$ & $27.9 \pm 15.1$ & 0.487 \\
\hline Postop & $8.9 \pm 4.5$ & $10.9 \pm 6.8$ & 0.161 \\
\hline Follow-up & $9.1 \pm 4.7$ & $11.0 \pm 6.8$ & 0.178 \\
\hline Change $e^{a)}$ & $16.1 \pm 13.7$ & $17.0 \pm 10.3$ & 0.800 \\
\hline \multicolumn{4}{|c|}{ Thoracic kyphosis $(\mathrm{T} 5-\mathrm{T} 12)\left({ }^{\circ}\right)$} \\
\hline Preop & $26.9 \pm 13.0$ & $25.7 \pm 12.2$ & 0.725 \\
\hline Postop & $32.6 \pm 11.1$ & $34.0 \pm 9.2$ & 0.625 \\
\hline Follow-up & $37.8 \pm 13.4$ & $33.0 \pm 11.8$ & 0.146 \\
\hline Change $^{\text {a) }}$ & $5.7 \pm 9.2$ & $8.3 \pm 8.9$ & 0.286 \\
\hline Pelvic incidence $\left({ }^{\circ}\right)$ & $54.1 \pm 11.7$ & $55.5 \pm 12.9$ & 0.685 \\
\hline \multicolumn{4}{|l|}{ Pelvic tilt $\left({ }^{\circ}\right)$} \\
\hline Preop & $33.5 \pm 9.7$ & $32.6 \pm 13.5$ & 0.736 \\
\hline Postop & $25.5 \pm 11.9$ & $26.4 \pm 12.8$ & 0.798 \\
\hline Follow-up & $26.3 \pm 11.3$ & $27.4 \pm 12.4$ & 0.745 \\
\hline Change $^{\text {al }}$ & $8.0 \pm 9.0$ & $6.2 \pm 11.5$ & 0.483 \\
\hline \multicolumn{4}{|l|}{ Lumbar lordosis $\left({ }^{\circ}\right)$} \\
\hline Preop & $19.6 \pm 18.3$ & $18.3 \pm 23.3$ & 0.808 \\
\hline Postop & $42.7 \pm 10.8$ & $41.9 \pm 11.0$ & 0.791 \\
\hline Follow-up & $41.2 \pm 11.9$ & $41.2 \pm 12.0$ & 0.985 \\
\hline Change $^{\text {a) }}$ & $23.1 \pm 20.3$ & $23.6 \pm 19.5$ & 0.923 \\
\hline \multicolumn{4}{|c|}{ Proximal junctional angle $\left(^{\circ}\right)$} \\
\hline Preop & $8.5 \pm 7.2$ & $8.3 \pm 6.1$ & 0.923 \\
\hline Postop & $12.4 \pm 5.9$ & $9.7 \pm 6.8$ & 0.130 \\
\hline Follow-up & $27.9 \pm 7.2$ & $11.7 \pm 6.7$ & $<0.001^{c \mid}$ \\
\hline Change ${ }^{\text {a) }}$ & $3.9 \pm 5.0$ & $1.4 \pm 3.9$ & 0.060 \\
\hline
\end{tabular}

Values are presented as mean \pm standard deviation.

PJK, proximal junctional kyphosis; Preop, preoperative; Postop, postoperative. ${ }^{\text {al }}$ Change between preoperation and postoperation. ${ }^{b}$ Coronal Cobb angle of the

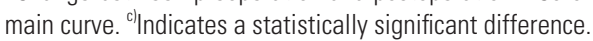


Table 4. Multivariate analysis of risk factors for PJK

\begin{tabular}{lcccc} 
Variable & PJK $(n=19)$ & Odds ratio & $(95 \%$ confidence interval) & $p$-value \\
History of vertebral compression fracture & 7 & $4.36(0.78-24.43)$ & 0.094 \\
\hline No. of interbody fusion & $5.1 \pm 1.3$ & $0.76(0.43-1.36)$ & 0.359 \\
\hline Corpectomy & 3 & $2.25(0.14-36.47)$ & 0.569 \\
\hline Lowest instrumented vertebrae (pelvis) & 18 & $18.46(1.54-221.32)$ & $0.021^{\text {a) }}$ \\
\hline Postoperative Cobb angle $\left({ }^{\circ}\right)^{b)}$ & $8.9 \pm 4.5$ & $0.96(0.87-1.05)$ & 0.374 \\
\hline
\end{tabular}

Values are presented as number or mean \pm standard deviation, unless otherwise stated. PJK, proximal junctional kyphosis.

${ }^{a}$ Indicates a statistically significant difference. ${ }^{b}$ Coronal Cobb angle of the main curve.

Table 5. Comparisons of clinical outcomes between the PJK and no-PJK groups

\begin{tabular}{|c|c|c|c|}
\hline Variable & $\begin{array}{c}\text { PJK } \\
(n=19)\end{array}$ & $\begin{array}{c}\text { No-PJK } \\
(n=55)\end{array}$ & $p$-value \\
\hline \multicolumn{4}{|c|}{ Preoperative JOABPEQ score } \\
\hline Low back pain & $24.2 \pm 19.8$ & $35.5 \pm 30.2$ & 0.306 \\
\hline Lumbar function & $48.7 \pm 30.4$ & $54.6 \pm 28.9$ & 0.497 \\
\hline Walking ability & $15.9 \pm 14.7$ & $31.7 \pm 24.4$ & $0.033^{a)}$ \\
\hline Social life function & $30.8 \pm 15.9$ & $43.6 \pm 17.1$ & $0.014^{a)}$ \\
\hline Mental health & $36.2 \pm 21.8$ & $43.7 \pm 18.2$ & 0.134 \\
\hline \multicolumn{4}{|l|}{ Preoperative VAS } \\
\hline Low back pain & $69.0 \pm 19.3$ & $64.4 \pm 24.7$ & 0.594 \\
\hline Leg pain & $67.9 \pm 32.4$ & $52.3 \pm 29.8$ & 0.164 \\
\hline Leg numbness & $34.1 \pm 37.8$ & $56.5 \pm 32.8$ & 0.076 \\
\hline \multicolumn{4}{|c|}{ JOABPEO effectiveness rate (\%) } \\
\hline Low back pain & 69.2 & 72.3 & 0.826 \\
\hline Lumbar function & 30.8 & 33.3 & 0.861 \\
\hline Walking ability & 61.5 & 68.8 & 0.623 \\
\hline Social life function & 46.2 & 40.8 & 0.729 \\
\hline Mental health & 30.8 & 36.7 & 0.689 \\
\hline \multicolumn{4}{|c|}{ Postoperative VAS improvement } \\
\hline Low back pain & $11.6 \pm 27.9$ & $42.7 \pm 42.2$ & $0.013^{\text {a) }}$ \\
\hline Leg pain & $24.2 \pm 35.8$ & $26.2 \pm 40.6$ & 0.892 \\
\hline Leg numbness & $6.0 \pm 35.9$ & $22.6 \pm 39.1$ & 0.239 \\
\hline
\end{tabular}

Values are presented as mean \pm standard deviation or as $\%$.

PJK, proximal junctional kyphosis; JOABPEQ, Japanese Orthopedic Association Back Pain Evaluation Questionnaire; VAS, Visual Analog Scale.

alIndicates a statistically significant difference.

pelvis was a significant risk factor for the onset of PJK (Table 4).

With respect to clinical outcome, both groups showed improvement in scores of all domains in the JOABPEQ postoperatively, regardless of the presence/absence of $\mathrm{PJK}$, and no between-group difference was observed in effectiveness rates (Table 5). For VAS scores, however, postoperative VAS improvement of low back pain was significantly lower in the PJK group than in the no-PJK group (Table 5).

\section{Discussion}

The prevalence of PJK during the study period following OLIF for ASD was 25.7\%, which was consistent with previous studies [11-17]. Regarding PJK risk factors, comparing PJK and no-PJK patients, the former had a higher trend of fusion to the pelvis, and a history of VCF.

LLIF is not only less invasive, utilizing a minimally lateral retroperitoneal approach, but also has several advantages for deformity correction as it allows the extensive release of the intervertebral disc, placement of a large interbody graft $[7,8]$, and high fusion rate [9]. We used OLIF which allowed not only aggressive deformity correction, but also the extension of the indication for surgery to older patients. Several previous reports have shown that greater deformity correction $[14,15]$ and older age $[12,14]$ are risk factors for PJK. In the present study, we performed large deformity corrections as in these previous reports, but the age of our patients was much higher. However, the prevalence of PJK in our study was not higher than noted in previous studies [11-17]. From this result, we estimate that a strong anterior support with a large interbody graft, and high fusion capacity with OLIF could lessen the stress at the proximal junction of the fused segment, and it resulted in a relatively low prevalence of PJK.

Our study showed that fusion to the pelvis was the most important risk factor for PJK, and several studies support our findings $[12,16,17]$. Yagi et al. $[16,17]$ reviewed patients with adult idiopathic scoliosis treated with long instrumented spinal fusion, and they found that fusion to the sacrum was a risk factor for PJK. Bridwell et al. [12] 
Table 6. Comparison between group FP and group NFP

\begin{tabular}{|c|c|c|c|}
\hline Variable & Group FP (n=52) & Group NFP (n=22) & $p$-value \\
\hline Age (yr) & $72.6 \pm 7.5$ & $75.9 \pm 5.4$ & $0.037^{\mathrm{a})}$ \\
\hline \multicolumn{4}{|l|}{ Sex } \\
\hline Male & 7 & 2 & 0.891 \\
\hline Female & 45 & 20 & \\
\hline Body mass index $\left(\mathrm{kg} / \mathrm{m}^{2}\right)$ & $23.2 \pm 3.9$ & $22.0 \pm 2.3$ & 0.105 \\
\hline \multicolumn{4}{|l|}{ History } \\
\hline Neurodegenerative disease & 3 & 0 & 0.613 \\
\hline Collagen disease & 2 & 1 & 0.613 \\
\hline Vertebral compression fracture & 10 & 3 & 0.563 \\
\hline Proximal femoral fracture & 1 & 0 & 0.655 \\
\hline No. of fused segments & $8.4 \pm 3.3$ & $6.1 \pm 1.8$ & $<0.001^{\text {a) }}$ \\
\hline No. of interbody fusions & $5.2 \pm 1.1$ & $3.5 \pm 0.8$ & $<0.001^{\text {a) }}$ \\
\hline No. of oblique lateral interbody fusions & $4.3 \pm 1.1$ & $3.5 \pm 0.9$ & $0.002^{a)}$ \\
\hline Corpectomies & 4 & 0 & 0.438 \\
\hline Posterior column osteotomy & 8 & 0 & 0.124 \\
\hline \multicolumn{4}{|l|}{ Upper instrumented vertebrae } \\
\hline$-\mathrm{T5}$ & 9 & 0 & 0.114 \\
\hline T6-T11 & 26 & 13 & \\
\hline T12- & 17 & 9 & \\
\hline \multicolumn{4}{|l|}{ Posterior procedure } \\
\hline All percutaneous & 0 & 7 & $<0.001^{\text {a) }}$ \\
\hline Hybrid & 44 & 15 & \\
\hline Full open & 8 & 0 & \\
\hline \multicolumn{4}{|l|}{ Sagittal vertical axis (mm) } \\
\hline Preop & $123.7 \pm 86.7$ & $89.0 \pm 84.8$ & 0.117 \\
\hline Postop & $53.9 \pm 41.4$ & $69.7 \pm 50.7$ & 0.205 \\
\hline Follow-up & $64.3 \pm 53.9$ & $65.2 \pm 52.1$ & 0.946 \\
\hline Change $^{\mathrm{b} /}$ & $71.9 \pm 88.7$ & $19.3 \pm 77.6$ & $0.019^{a)}$ \\
\hline \multicolumn{4}{|l|}{ Coronal vertical axis (mm) } \\
\hline Preop & $27.5 \pm 27.2$ & $19.5 \pm 15.6$ & 0.117 \\
\hline Postop & $20.4 \pm 16.8$ & $26.3 \pm 17.9$ & 0.179 \\
\hline Follow-up & $15.3 \pm 16.1$ & $13.2 \pm 11.1$ & 0.517 \\
\hline Change $^{b l}$ & $16.2 \pm 35.8$ & $3.9 \pm 30.1$ & 0.135 \\
\hline \multicolumn{4}{|l|}{ Cobb angle $\left({ }^{\circ}\right)^{c)}$} \\
\hline Preop & $25.5 \pm 15.9$ & $31.1 \pm 13.4$ & 0.122 \\
\hline Postop & $10.3 \pm 6.7$ & $10.5 \pm 5.5$ & 0.933 \\
\hline Follow-up & $10.4 \pm 6.7$ & $10.9 \pm 5.7$ & 0.770 \\
\hline Change $^{\text {b) }}$ & $15.1 \pm 11.3$ & $20.7 \pm 10.1$ & 0.051 \\
\hline \multicolumn{4}{|l|}{ Thoracic kyphosis $(\mathrm{T} 5-\mathrm{T} 12)\left({ }^{\circ}\right)$} \\
\hline Preop & $26.4 \pm 12.5$ & $25.1 \pm 12.0$ & 0.698 \\
\hline Postop & $33.3 \pm 9.2$ & $34.3 \pm 10.9$ & 0.730 \\
\hline
\end{tabular}


Table 6. Continued

\begin{tabular}{|c|c|c|c|}
\hline Variable & Group FP (n=52) & Group NFP (n=22) & $p$-value \\
\hline Follow-up & $34.7 \pm 11.3$ & $33.1 \pm 14.7$ & 0.649 \\
\hline Change $^{b)}$ & $7.0 \pm 8.4$ & $9.1 \pm 10.3$ & 0.392 \\
\hline Pelvic incidence $\left({ }^{\circ}\right)$ & $54.5 \pm 13.4$ & $56.6 \pm 10.4$ & 0.485 \\
\hline \multicolumn{4}{|l|}{ Pelvic tilt $\left({ }^{\circ}\right)$} \\
\hline Preop & $32.4 \pm 11.8$ & $33.9 \pm 14.4$ & 0.667 \\
\hline Postop & $25.4 \pm 13.5$ & $28.0 \pm 9.7$ & 0.348 \\
\hline Follow-up & $26.2 \pm 12.9$ & $29.3 \pm 9.9$ & 0.254 \\
\hline Change $^{\text {b) }}$ & $7.0 \pm 10.0$ & $5.9 \pm 13.0$ & 0.718 \\
\hline \multicolumn{4}{|l|}{ Lumbar lordosis $\left({ }^{\circ}\right)$} \\
\hline Preop & $17.3 \pm 23.1$ & $22.0 \pm 19.2$ & 0.364 \\
\hline Postop & $43.4 \pm 10.9$ & $39.0 \pm 10.5$ & 0.115 \\
\hline Follow-up & $42.8 \pm 11.7$ & $37.4 \pm 11.9$ & 0.075 \\
\hline Change $^{\text {b) }}$ & $26.2 \pm 20.9$ & $17.0 \pm 14.4$ & $0.035^{\text {a) }}$ \\
\hline
\end{tabular}

Values are presented as mean \pm standard deviation.

Group FP, group with fusion to the pelvis; group NFP, group without fusion to the pelvis.

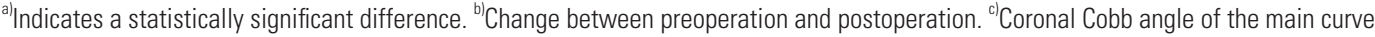

also reported that fusion to the sacrum was associated with PJK exceeding $20^{\circ}$ after primary surgical treatment for adult idiopathic/degenerative scoliosis. Therefore, we added an analysis of fusion to the pelvis. We divided the subjects into two groups: with fusion to the pelvis (group FP) or without fusion to the pelvis (group NFP), and then evaluated between-group differences in the same way as the analysis for PJK (Table 6). Consequently, the number of fused segments, interbody fusions, OLIFs, and changes of sagittal vertical axis and lumbar lordosis were significantly larger in group FP than in group NFP. In addition, a wider surgical field was made in group FP. Accordingly, we presume in group FP that a greater deformity correction increases stress concentrations at the proximal end of the fusion, and wider exposure of the surgical field causes more severe back muscle injury, which can result in PJK. However, there are several benefits of fusion to the pelvis, such as avoiding sagittal decompensation and distal junctional degeneration after long spinal fusion.

Moreover, our findings indicated that a history of VCF was another additional risk factor for PJK. Although, to the best of our knowledge, no studies have identified a history of VCF as a PJK risk factor, several studies indicated a relationship between PJK and low bone mineral density (BMD), which is the major cause of VCF. Yagi et al. [17] identified pre-existing low BMD as a significant risk factor for PJK after long instrumented spinal fusion.
O'Leary et al. [19] reported osteopenia as one of the risk factors for acute fractures at the proximal aspect of long pedicle screw constructs.

As mentioned above, fusion to the pelvis was identified as the most important risk factor for PJK. However, in many deformity cases, fusion to the pelvis is often necessary to achieve appropriate lumbar lordosis and sagittal balance, and to avoid distal adjacent segment disease. Therefore, countermeasures for this problem are important. Some trials report that using hooks in the UIV for long-segment instrumentation is advantageous in lessening the PJK risk $[13,18]$. Additionally, some trials reported the effectiveness of vertebral cement augmentation (vertebroplasty) at the UIV and proximal adjacent vertebrae to prevent PJK or PJF after long-segment spinal instrumentation $[22,23]$. In addition, the indication for LLIF in correction surgery has been extended to older patients because it is less invasive. However, surgery for patients with a history of VCF predisposes to PJK according to our study. Therefore, parathyroid hormone formulation may be administered in severely osteoporotic patients with a history of VCF for the prevention of PJK.

There are some limitations to this study. First, this study included a relatively small number of cases. A larger, multicenter study may be desirable to examine in more detail the risk factors for PJK after correction surgery with OLIF in patients with ASD. However, the present study 
has some advantages in that the surgical method and postoperative rehabilitation were appreciably uniform, because surgery was performed by a single surgeon in a single institution. Second, measurement of BMD was not performed in all surgical cases. Thus, we substituted a previous history of VCF for BMD as an indicator of bone strength. It is desirable to investigate patients' BMD data to estimate their bone strength.

\section{Conclusions}

The prevalence of PJK after OLIF for ASD was consistent with previous studies. The present study demonstrated that fusion to the pelvis was the most important risk factor, and a history of VCF served as another additional risk factor for PJK. Large deformity correction using the OLIF procedure does not seem to increase PJK risk. However, preventing $\mathrm{PJK}$ is particularly important in patients with fusion to the pelvis, and a history of VCF.

\section{Conflict of Interest}

No potential conflict of interest relevant to this article was reported.

\section{Author Contributions}

Conception and design, data acquisition, and drafting of the manuscript: Koike Y, Kotani Y; analysis of data: Koike $\mathrm{Y}$; and critical revision and supervision: Terao $\mathrm{H}$, Iwasaki $\mathrm{N}$.

\section{References}

1. Schwab F, Dubey A, Gamez L, et al. Adult scoliosis: prevalence, SF-36, and nutritional parameters in an elderly volunteer population. Spine (Phila Pa 1976) 2005;30:1082-5.

2. Schwab F, Ungar B, Blondel B, et al. Scoliosis Research Society-Schwab adult spinal deformity classification: a validation study. Spine (Phila Pa 1976) 2012;37:1077-82.

3. Smith JS, Lafage V, Shaffrey CI, et al. Outcomes of operative and nonoperative treatment for adult spinal deformity: a prospective, multicenter, propensitymatched cohort assessment with minimum 2-year follow-up. Neurosurgery 2016;78:851-61.
4. Baron EM, Albert TJ. Medical complications of surgical treatment of adult spinal deformity and how to avoid them. Spine (Phila Pa 1976) 2006;31:S106-18.

5. Lenke LG, Sides BA, Koester LA, Hensley M, Blanke KM. Vertebral column resection for the treatment of severe spinal deformity. Clin Orthop Relat Res 2010;468:687-99.

6. Cho KJ, Bridwell KH, Lenke LG, Berra A, Baldus C. Comparison of Smith-Petersen versus pedicle subtraction osteotomy for the correction of fixed sagittal imbalance. Spine (Phila Pa 1976) 2005;30:2030-7.

7. Castro C, Oliveira L, Amaral R, Marchi L, Pimenta L. Is the lateral transpsoas approach feasible for the treatment of adult degenerative scoliosis? Clin Orthop Relat Res 2014;472:1776-83.

8. Tempel ZJ, Gandhoke GS, Bonfield CM, Okonkwo DO, Kanter AS. Radiographic and clinical outcomes following combined lateral lumbar interbody fusion and posterior segmental stabilization in patients with adult degenerative scoliosis. Neurosurg Focus 2014;36:E11.

9. Berjano P, Langella F, Damilano M, et al. Fusion rate following extreme lateral lumbar interbody fusion. Eur Spine J 2015;24 Suppl 3:369-71.

10. Kim KT, Jo DJ, Lee SH, Seo EM. Oblique retroperitoneal approach for lumbar interbody fusion from L1 to S1 in adult spinal deformity. Neurosurg Rev 2018;41:355-63.

11. Glattes RC, Bridwell KH, Lenke LG, Kim YJ, Rinella A, Edwards C 2nd. Proximal junctional kyphosis in adult spinal deformity following long instrumented posterior spinal fusion: incidence, outcomes, and risk factor analysis. Spine (Phila Pa 1976) 2005;30:1643-9.

12. Bridwell KH, Lenke LG, Cho SK, et al. Proximal junctional kyphosis in primary adult deformity surgery: evaluation of 20 degrees as a critical angle. Neurosurgery 2013;72:899-906.

13. Hassanzadeh H, Gupta S, Jain A, El Dafrawy MH, Skolasky RL, Kebaish KM. Type of anchor at the proximal fusion level has a significant effect on the incidence of proximal junctional kyphosis and outcome in adults after long posterior spinal fusion. Spine Deform 2013;1:299-305.

14. Kim HJ, Bridwell KH, Lenke LG, et al. Patients with proximal junctional kyphosis requiring revision surgery have higher postoperative lumbar lordosis and larger sagittal balance corrections. Spine (Phila Pa 
1976) 2014;39:E576-80.

15. Maruo K, Ha Y, Inoue S, et al. Predictive factors for proximal junctional kyphosis in long fusions to the sacrum in adult spinal deformity. Spine (Phila Pa 1976) 2013;38:E1469-76.

16. Yagi M, Akilah KB, Boachie-Adjei O. Incidence, risk factors and classification of proximal junctional kyphosis: surgical outcomes review of adult idiopathic scoliosis. Spine (Phila Pa 1976) 2011;36:E60-8.

17. Yagi $M$, King $A B$, Boachie-Adjei O. Incidence, risk factors, and natural course of proximal junctional kyphosis: surgical outcomes review of adult idiopathic scoliosis: minimum 5 years of follow-up. Spine (Phila Pa 1976) 2012;37:1479-89.

18. Helgeson MD, Shah SA, Newton PO, et al. Evaluation of proximal junctional kyphosis in adolescent idiopathic scoliosis following pedicle screw, hook, or hybrid instrumentation. Spine (Phila Pa 1976) 2010;35:177-81.

19. O'Leary PT, Bridwell KH, Lenke LG, et al. Risk factors and outcomes for catastrophic failures at the top of long pedicle screw constructs: a matched cohort analysis performed at a single center. Spine (Phila Pa 1976) 2009;34:2134-9.
20. Elmekaty M, Kotani Y, Mehy EE, et al. Clinical and radiological comparison between three different minimally invasive surgical fusion techniques for single-level lumbar isthmic and degenerative spondylolisthesis: minimally invasive surgical posterolateral fusion versus minimally invasive surgical transforaminal lumbar interbody fusion versus midline lumbar fusion. Asian Spine J 2018;12:870-9.

21. Fukui M, Chiba K, Kawakami M, et al. JOA back pain evaluation questionnaire (JOABPEQ)/JOA cervical myelopathy evaluation questionnaire (JOACMEQ): the report on the development of revised versions. April 16, 2007. The subcommittee of the clinical outcome committee of the Japanese orthopaedic association on low back pain and cervical myelopathy evaluation. J Orthop Sci 2009;14:348-65.

22. Hart RA, Prendergast MA, Roberts WG, Nesbit GM, Barnwell SL. Proximal junctional acute collapse cranial to multi-level lumbar fusion: a cost analysis of prophylactic vertebral augmentation. Spine J 2008;8:875-81.

23. Kebaish KM, Martin CT, O'Brien JR, LaMotta IE, Voros GD, Belkoff SM. Use of vertebroplasty to prevent proximal junctional fractures in adult deformity surgery: a biomechanical cadaveric study. Spine J 2013;13:1897-903. 